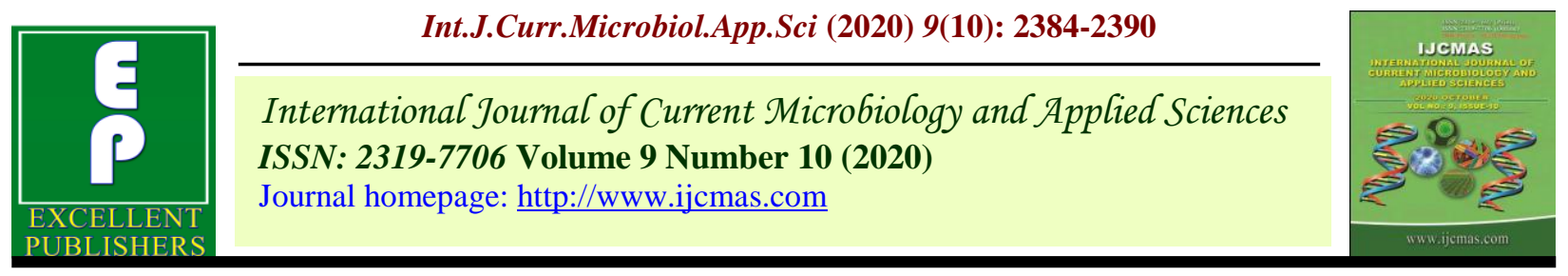

Original Research Article

https://doi.org/10.20546/ijcmas.2020.910.285

\title{
Influence of Growth Retardants on Flowering of Potted Alstroemeria (Alstroemeria hybrida L.)
}

\author{
Raiz Ahmed Lone*, Imtiyaz Tahir Nazki, Nelofar and Gazanfar Gani
}

Division of Floriculture and Landscape Architecture, Faculty of Horticulture, SKUAST-K, Shalimar Campus, Srinagar 190025, Jammu and Kashmir, India.

*Corresponding author

\begin{abstract}
A B S T R A C T
An experiment was conducted to evaluate the influence of different concentrations of Alar (Diaminozide) and Ethephon (Ethrel) as spray applications on two cultivars of pot grown Alstroemeria to study their effect on different flowering parameters under shaded conditions during two successive flushes in the year 2016 - 2017 at the Research farm of Division of Floriculture and Landscape Architecture, Sher-e-Kashmir University of Agricultural Sciences and Technology of Kashmir, Shalimar Campus Srinagar. Fourteen different treatments with two cultivars (Pluto, New Pink) were used with four concentrations of Alar $(0,500$, 1000 and 1500ppm) and Ethephon (0,1000, 1500, $2000 \mathrm{ppm})$ were replicated thrice in a Completely Randomized Design. The investigation revealed that with application of Alar at $1500 \mathrm{ppm}$ maximum days to flower bud formation, number of cymes/inflorescence, number of florets/cyme, diameter of primary floret, diameter of flowering shoots, number of nodes on generative shoots, duration of flowering and pot presentability was observed in both cultivars in successive flushes followed by Ethephon 2000 ppm and Alar at1000ppm.
\end{abstract}

\section{Keywords}

Alstroemeria, Pot plant, Growth retardants, Alar, Ethephon

\section{Article Info}

Accepted:

17 September 2020

Available Online:

10 October 2020

\section{Introduction}

Alstroemeria hybrida L. (1) commonly known as the Peruvian Lily or the Lily of the Incas is a native of South America. The genus is a rhizomatous monocot and belongs to family Alstroemeriaceae (2). Previously, Alstroemeria was assigned to family Amaryllidaceae and Liliaceae $(3,4)$. Alstroemeria plants are widely cultivated in many countries especially in Western Europe and North America and popularity has increased recently due to its long-vase life, large variety of colours and low energy requirement during cultivation (5). In Kenya in terms of popularity and foreign exchange Alstroemeria stands third after roses and statice (6). The popularity of this flower is still growing and has attained the status of one of the ten most important cut flowers in the world. 
In the late 1980s, several breeders started work on developing seed propagated Alstroemeria cultivars which would be suitable for pot culture. Konst of Netherlands has been the pioneer breeding company in the world to introduce a series of successful dwarf Alstroemeria cultivars belonging to Inca series which are suitable for pot culture. Earliest dwarf cultivars include Rosalina and Dorotea. Although Alstroemeria cultivars available for pot culture are 50 per cent shorter than cut flower varieties, plant height is still excessive for most markets. Moreover, genetically dwarf plants are still beyond the reach of common grower as they are strictly protected by plant breeder rights. Chemical growth retardants have been known to be useful in manipulating shape, size and form of ornamental crops (7). They permit a direct approach to growth control by retarding internodal elongation without seriously disrupting growth processes. Most of the commercially available growth retardants are primarily used to retard plant, height regulate flowering and stimulate lateral or basal branches. Major work on standardization of growing media, lighting and use of growth retardants to control growth and flowering has mostly been done on cut flower varieties which are tall in growth habit $(8,9)$. In Alstroemeria growing regions of India including Kashmir most of the cultivars introduced in 90's are tall cut flower types. In order to explore their potential as potted plants use of growth retardant to control their height is imperative.

\section{Materials and Methods}

The present investigation was carried out at the Research farm of Division of Floriculture and Landscape Architecture, Sher-e-Kashmir University of Agricultural Sciences and Technology of Kashmir, Shalimar Campus Srinagar, in 2017. Srinagar district of Jammu and Kashmir state is situated between $34^{\circ} 5^{`}$ - $34^{\circ} 7^{\prime}$ North latitude and $74^{\circ} 8^{`}-74^{\circ} 9^{`}$ East longitude at an altitude of 1558 meters above mean sea level. It is flanked on the South-East and North-East sides by the lofty Himalayan ranges. The SKUAST (K) Campus is situated at the base of these ranges towards the NorthEast side $15 \mathrm{kms}$ from Srinagar city. The organic carbon of the soil was found to be 0.98 per cent and $\mathrm{pH} / 6.93$. The climate of the area in general is temperate-cum Mediterranean and of continental type characterized by hot summers and severe winters. Hottest months are July and August during which temperature shoots up to $32^{\circ} \mathrm{C}$. The experiment was conducted in Completely Randomized Design, the total number of treatments were fourteen, two cultivars (Pluto, New Pink) were used with four concentrations of Alar (0, 500, 1000 and 1500 ppm) and Ethephon (0, 1000, 1500, 2000 $\mathrm{ppm}$ ) to see their effect on flowering through spray application. Rhizomes of $3-4 \mathrm{~cm}$ length, containing 1-2 sprouted shoots, 3-4 fleshy storage roots and sufficient number of fibrous roots were planted in $20 \mathrm{~cm}$ diameter pots ( 1 per pot) in a well prepared potting mixture consisting of equal parts by volume of soil, FYM, sand, cocopeat and vermicompost in November 2016. In all pots the growing shoots were trimmed to $5-\mathrm{cm}$ height to bring uniformity in the growth pattern and only 10 healthy generative shoots were retained in each pot to avoid overcrowding and competition. Two sprays of each chemical were made, first when the shoots were $10-15 \mathrm{~cm}$ tall and second 20 days after the first spray. Same set of treatments were repeated in both cultivars as soon as growth resumed after dormancy in August. Thin and weak shoots were periodically removed.

The solutions of Alar (daminozide) $1500 \mathrm{ppm}$ and Ethephon 2000 ppm was prepared by dissolving 1500 milligrams of Alar in 1000 $\mathrm{ml}$ distilled water and by dissolving Ethephon 
$2000 \mathrm{ml}$ in $1000 \mathrm{ml}$ distilled water and rest of concentrations were prepared accordingly. The plants were sprayed until droplet formation on the leaves. The observations were recorded on plant height, plant spread, shoot length, number of leaves/shoots, shoot diameter and chlorophyll content of leaves. The statistical analysis was done using Completely Randomized Design at 5\% level of significance.

\section{Results and Discussion}

Results presented in Table 1 revealed that plants of cv. New Pink performs better in terms of flower production than Pluto in both the flushes. Application of growth retardants at higher concentrations delayed flower bud formation. Cultivar New Pink reached flower bud formation in 227.89 and 72.33 days) with Alar1500 ppm sprays during first and second flush respectively followed by 225.44 and 70.33 days with application of Ethephon 2000 ppm in comparison to 215.78 and 62.66 days recorded in control while $\mathrm{cv}$. Pluto took 237.33 and 80.67days to flower bud formation with $1500 \mathrm{ppm}$ Alar sprays followed by 235.22 and 78.22 days with Ethephon $2000 \mathrm{ppm}$ in comparison to 226.22 and 73.33 in control during successive flushes. Growth retardants significantly improved the number of cymes/inflorescence in both the cultivars. Cultivar New Pink exhibited more number of cymes/ inflorescence (6.00 and 5.33) with Alar 1500 ppm which was at par with 5.55 and 4.66 recorded with Ethephon 2000 ppm and 5.44 and 4.89 with Alar 1000 ppm during first and second flush respectively. In cv. Pluto more number of cymes 5.66 and 4.55 was also recorded with Alar 1500 ppm sprays during successive flushes which was found to be at par (4.22) with Ethephon 2000 ppm and (4.11) with Alar 1000 ppm during second flush. Increased number of florets/cyme was obtained with Alar 1500ppm in both cultivars.
In cv. New Pink application of Alar 1500 recorded in higher number of florets/cymes (3.55 and 3.33) which was at however par with Ethephon 2000 ppm (3.22 and 3.11) and Alar 1000 ppm (3.00 and 2.89) during successive flushes. Similarly in cv. Pluto higher average number of florets/cyme (3.11 and 3.00) was recorded with Alar 1500 ppm which was statistically at par with Ethephon 2000 ppm (3.00 and 2.89) and Alar 1000 ppm (2.89 and 2.67).Cultivar New Pink bore flowers with average primary floret diameter of $7.14 \mathrm{~cm}$ and $7.00 \mathrm{~cm}$ during successive flushes with Alar 1500 ppm followed by 6.90 and $6.80 \mathrm{~cm}$ with Ethephon $2000 \mathrm{ppm}$ in comparison to 6.55 and $6.44 \mathrm{~cm}$ in control. Increased diameter of primary floret $5.52 \mathrm{~cm}$ and $5.43 \mathrm{~cm}$ was recorded in $\mathrm{cv}$. Pluto by application of Alar $1500 \mathrm{ppm}$ which was at par with Ethephon 2000ppm $(5.41 \mathrm{~cm}$ and $5.34 \mathrm{~cm})$ and Alar $1000 \mathrm{ppm}(5.40 \mathrm{~cm}$ and $5.33 \mathrm{~cm})$ in successive flushes.A mean diameter of $7.03 \mathrm{~mm}$ and $6.92 \mathrm{~mm}$ flowering shoot was recorded in cv. New pink with Alar $1500 \mathrm{ppm}$ which was at par with 6.93 and $6.86 \mathrm{~mm}$ under Ethephon $2000 \mathrm{ppm}$ and 6.69 and $6.44 \mathrm{~mm}$ with Alar $1000 \mathrm{ppm}$ in successive flushes. In cv. Pluto improved diameter 9.03 and $8.92 \mathrm{~mm}$ of flowering shoots was recorded with application of Alar $1500 \mathrm{ppm}$ spray which was found to be at par (8.96 and $8.88 \mathrm{~mm}$ ) with Ethephon $2000 \mathrm{ppm}$ and (8.82 and $8.75 \mathrm{~mm})$ with Alar $1000 \mathrm{ppm}$. Minimum diameter of 6.00 and $5.91 \mathrm{~mm}$ in cv. New Pink and 8.10 and $7.99 \mathrm{~mm}$ of flowering shoots in cv. Pluto were recorded during successive flushes in control plants. Higher number of nodes on generative shoots (30.22 and 29.33) recorded in cv. New Pink with Alar 1500 ppm was followed by 27.44 and 26.77 with Ehtephon $2000 \mathrm{ppm}$ in comparison to 21.44 and 20.55 in control. Cultivar Pluto bore 17.44 and 16.66 number of nodes on generative shoots with application of Alar $1500 \mathrm{ppm}$ in successive flushes which was at par 16.44 and 15.77 with 
Ethephon 2000 ppm and 16.33 and 15.77 with Alar 1000 ppm (Table 2).

Maximum flower duration of 71.11 and 66.22 days was recorded in cv. New Pink during successive flushes with Alar 1500 ppm followed by 65.44 and 60.89 days with Ethephon $2000 \mathrm{ppm}$ in comparison to 53.33 and 48.44 days in control. Application of Alar 1500 sprays also results in maximum (61.11 and 56.89 days) duration of flowering in cv. Pluto followed by 57.22 and 52.33 days with Ethephon $2000 \mathrm{ppm}$ in comparison to 44.55 and 40.00 days recorded in control plants. Pot presentabilty was worked out by assigning scores to different treatments out of maximum score of 100. An appraisal of data in Table 3 shows that plants of cultivar New Pink were more presentable with a score of 82.33 and
79.66 with Alar $1500 \mathrm{ppm}$ followed by 79.44 and 76.88 with Ethephon in comparison to a score of 62.00 and 59.44 in control. In cv. Pluto improved pot presentability of 67.33 and 65.33 during successive flushes was recorded with Alar $1500 \mathrm{ppm}$ followed by 64.66 and 61.78 with Ethephon 2000 ppm in comparison to 54.77 and 52.22 in control.

Both growth retardants delayed the flower bud formation in Alstroemeria with maximum delay recorded with application of Alar @1500ppm during first and second flush respectively in both cultivars. A significant influence of growth retardants was also observed in all other flowering parameters like number of cymes/inflorescence and number of florets/cyme.

Table.1 Effect of growth retardants on days to flower bud formation, number of cymes/inflorescence and number of florets in Alstroemeria hybrida (L.)

\begin{tabular}{|c|c|c|c|c|c|c|}
\hline \multirow[t]{2}{*}{ Treatment details } & \multicolumn{2}{|c|}{$\begin{array}{l}\text { Days to flower bud } \\
\text { formation }\end{array}$} & \multicolumn{2}{|c|}{$\begin{array}{c}\text { No. of } \\
\text { cymes/inflorescence }\end{array}$} & \multicolumn{2}{|c|}{ No. of florets/cymes } \\
\hline & First Flush & First Flush & First Flush & $\begin{array}{l}\text { Second } \\
\text { Flush }\end{array}$ & First Flush & $\begin{array}{l}\text { Second } \\
\text { Flush }\end{array}$ \\
\hline New Pink & 215.78 & 62.66 & 4.33 & 3.33 & 2.33 & 2.11 \\
\hline New Pink (Alar@500ppm) & 221.00 & 67.22 & 5.11 & 4.11 & 2.89 & 2.77 \\
\hline New Pink (Alar@1000ppm) & 224.66 & 69.44 & 5.44 & 4.89 & 3.00 & 2.89 \\
\hline New Pink (Alar@1500ppm) & 227.89 & 72.33 & 6.00 & 5.33 & 3.55 & 3.33 \\
\hline New Pink (Ethephon@1000ppm) & 217.11 & 65.44 & 4.55 & 3.22 & 2.66 & 2.55 \\
\hline New Pink (Ethephon@1500ppm) & 221.66 & 68.55 & 5.00 & 4.00 & 2.78 & 2.44 \\
\hline New Pink (Ethephon@2000ppm) & 225.44 & 70.33 & 5.55 & 4.66 & 3.22 & 3.11 \\
\hline Pluto & 226.22 & 73.33 & 3.66 & 2.89 & 2.11 & 2.00 \\
\hline Pluto (Alar@500ppm) & 231.33 & 75.44 & 4.11 & 3.78 & 2.77 & 2.66 \\
\hline Pluto (Alar@1000ppm) & 234.33 & 77.11 & 4.89 & 4.11 & 2.89 & 2.67 \\
\hline Pluto (Alar@1500ppm) & 237.33 & 80.67 & 5.66 & 4.55 & 3.11 & 3.00 \\
\hline Pluto (Ethephon@1000ppm) & 229.22 & 74.44 & 3.89 & 3.55 & 2.44 & 2.33 \\
\hline Pluto (Ethephon@1500ppm) & 232.33 & 76.55 & 4.33 & 3.89 & 2.67 & 2.55 \\
\hline Pluto (Ethephon@ @2000ppm) & 235.22 & 78.22 & 5.00 & 4.22 & 3.00 & 2.89 \\
\hline C.D (0.05) & 1.722 & 1.520 & 0.606 & 0.622 & 0.580 & 0.541 \\
\hline
\end{tabular}


Table.2 Effect of growth retardants on diameter of primary floret, diameter of flowering shoots and number of nodes on generative shoots Alstroemeria hybrida (L.)

\begin{tabular}{|c|c|c|c|c|c|c|}
\hline \multirow[t]{2}{*}{ Treatment details } & \multicolumn{2}{|c|}{ Dia. of primary floret (cm) } & \multicolumn{2}{|c|}{$\begin{array}{c}\text { Dia. of flowering shoots } \\
(\mathbf{m m})\end{array}$} & \multicolumn{2}{|c|}{$\begin{array}{l}\text { No. of nodes on } \\
\text { generative shoots }\end{array}$} \\
\hline & First Flush & First Flush & First Flush & $\begin{array}{l}\text { Second } \\
\text { Flush }\end{array}$ & First Flush & $\begin{array}{l}\text { Second } \\
\text { Flush }\end{array}$ \\
\hline New Pink & 6.55 & 6.44 & 6.00 & 5.91 & 21.44 & 20.55 \\
\hline New Pink (Alar@500ppm) & 6.78 & 6.70 & 6.33 & 6.26 & 24.66 & 23.77 \\
\hline New Pink (Alar@1000ppm) & 6.83 & 6.73 & 6.69 & 6.44 & 27.22 & 26.66 \\
\hline New Pink (Alar@1500ppm) & 7.14 & 7.00 & 7.03 & 6.92 & 30.22 & 29.33 \\
\hline New Pink (Ethephon@1000ppm) & 6.62 & 6.56 & 6.21 & 6.11 & 23.00 & 22.44 \\
\hline New Pink (Ethephon@1500ppm) & 6.75 & 6.61 & 6.47 & 6.36 & 25.11 & 24.33 \\
\hline New Pink (Ethephon @ 2000ppm) & 6.90 & 6.80 & 6.93 & 6.86 & 27.44 & 26.77 \\
\hline Pluto & 5.21 & 5.14 & 8.10 & 7.99 & 12.88 & 11.88 \\
\hline Pluto (Alar@500ppm) & 5.33 & 5.25 & 8.59 & 8.51 & 14.77 & 14.00 \\
\hline Pluto (Alar@1000ppm) & 5.41 & 5.34 & 8.82 & 8.75 & 16.33 & 15.77 \\
\hline Pluto (Alar@1500ppm) & 5.52 & 5.43 & 9.03 & 8.92 & 17.44 & 16.66 \\
\hline Pluto (Ethephon@ 1000ppm) & 5.25 & 5.18 & 8.49 & 8.38 & 13.99 & 12.88 \\
\hline Pluto (Ethephon@1500ppm) & 5.32 & 5.26 & 8.70 & 8.59 & 15.66 & 14.89 \\
\hline Pluto (Ethephon@ @2000ppm) & 5.41 & 5.34 & 8.96 & 8.88 & 16.44 & 15.77 \\
\hline C.D (0.05) & 0.169 & 0.153 & 0.473 & 0.466 & 1.355 & 2.235 \\
\hline
\end{tabular}

Table.3 Effect of growth retardants on duration of flowering and pot presentability of Alstroemeria hybrida (L.).

\begin{tabular}{|l|c|c|c|c|}
\hline \multirow{2}{*}{ Treatment details } & \multicolumn{2}{|c|}{ Duration of flowering (days) } & \multicolumn{2}{c|}{ Pot Present ability } \\
\cline { 2 - 5 } & First Flush & First Flush & First Flush & Second Flush \\
\hline New Pink & 53.33 & 48.44 & 62.00 & 59.44 \\
\hline New Pink (Alar@500ppm) & 60.00 & 55.55 & 71.33 & 69.00 \\
\hline New Pink (Alar@1000ppm) & 65.11 & 60.44 & 76.22 & 73.66 \\
\hline New Pink (Alar@1500ppm) & $\mathbf{7 1 . 1 1}$ & $\mathbf{6 6 . 2 2}$ & $\mathbf{8 2 . 3 3}$ & $\mathbf{7 9 . 6 6}$ \\
\hline New Pink (Ethephon@1000ppm) & 56.33 & 52.22 & 68.33 & 65.78 \\
\hline New Pink (Ethephon@1500ppm) & 60.33 & 55.55 & 74.44 & 71.66 \\
\hline New Pink (Ethephon @2000ppm) & 65.44 & 60.89 & 79.44 & 76.88 \\
\hline Pluto & 44.55 & 40.00 & 54.77 & 52.22 \\
\hline Pluto (Alar@500ppm) & 53.33 & 48.77 & 59.33 & 57.00 \\
\hline Pluto(Alar@1000ppm) & 56.55 & 51.55 & 64.33 & 61.78 \\
\hline Pluto (Alar@1500ppm) & $\mathbf{6 1 . 1 1}$ & $\mathbf{5 6 . 8 9}$ & $\mathbf{6 7 . 3 3}$ & $\mathbf{6 5 . 3 3}$ \\
\hline Pluto (Ethephon@1000ppm) & 49.11 & 45.44 & 57.00 & 55.33 \\
\hline Pluto (Ethephon@1500ppm) & 53.77 & 48.89 & 61.00 & 59.22 \\
\hline Pluto (Ethephon @ 2000ppm) & 57.22 & 52.33 & 64.66 & 61.89 \\
\hline C.D(0.05) & $\mathbf{2 . 1 6 4}$ & $\mathbf{3 . 4 5 1}$ & $\mathbf{1 . 8 5 4}$ & $\mathbf{2 . 9 8 2}$ \\
\hline
\end{tabular}


Alar @ 1500ppm recorded maximum number of cymes/inflorescence, number of florets/cyme, diameter of primary floret, diameter of flowering shoots, nodes on generative shoots, duration of flowering and pot presentability followed by Ethephon @ 2000ppm in both cultivars. Cultivar New Pink took minimum days to flower bud formation and produced highest number of cymes/inflorescence, number of florets/cyme, diameter of flowering shoots, nodes on generative shoots, duration of flowering and exhibited superior pot presentability than $\mathrm{cv}$. Pluto. The difference in days to bud formation and other flowering parameters in the two flushes reflects the effect of difference in temperature and photoperiod prevalent during the two flushes.

Delay in flower bud appearance might be attributed to the suppression of apical dominance and increased vegetative growth in the form of primary and secondary branches by the growth retardants. (10) reported that delay of flowering is often observed following application of growth retardants, especially at very higher concentration. Similar results were recorded by (11) with Alar and Ethephon in dahlia, (12) with paclobutrazol in golden rod and (13) with $\mathrm{CCC}$ and $\mathrm{MH}$ in tulip, (14) in chrysanthemum with $\mathrm{CCC}$ and $\mathrm{MH}$, and (15) in oriental lily.

Influence of growth retardants on flowering parameters was reported by (16) who applied Alar (diaminozide) at the rate of $0.3 \mathrm{~g} /$ litre to 10 month old plants of Alstroemeria in early September and found that flower stalk length were reduced by $19-23 \mathrm{~cm}$ by all treatments. Similar results on control of flowering parameters have been reported by (9) while working with two dwarf Alstroemeria cultivars, after treating plants with diaminozide@2500 ppm spray. (17) also observed the effects of paclobutrazol (PP333) and B9 on decrease in stem elongation and delay in flowering in chrysanthemum. The study involved chrysanthemums planted in pots or in plots sprayed with PP333 (paclobutrazol) at 250-2000 ppm or B9 (daminozide) at $1500-5000 \mathrm{ppm}$. The authors reported that PP333 at 1000 ppm effectively inhibited growth, its effect varying with the number of sprays. It was further reported that treated plants were shorter, with a green leaf colour, delayed flowering and a longer flowering period. B9 also inhibited growth, but its effect was significantly less than that of PP333.

It is concluded that this study showed that among the two growth retardant Alar was more effective in improving number of cymes per inflorescence, number of florets per cyme, diameter of primary floret and flowering shoots, number of nodes on generative shoots with increased duration of flowering which in turn achieved better pot presentability.

\section{Competing interests}

Authors have declared that no competing interests exist.

\section{References}

1. Huxley A, Griffiths M, Levy M. Alstroemeria, In: The New Royal Horticultural Society Dictionary of Gardening. Stockton Press, New York. 1992; 1: 141.

2. Baily LH. Alstroemeria: Hortusthird. Macmillan Publishing Company, New York, USA. 1976; 62.

3. Stinson H. Alstroemeria cultivated in the United States. Herbertia. 1942; 9: 41-52.

4. Vonk Noordegraaf C. Bloemprodktie big Alstroemeria 'Water Fleming'. Doctor of Philosophy Thesis, Agriculture University, Wageningen, The Netherlands. 1981; 145.

5. Sung-Soo L, Sang-Il L, Se-Chan K, 
Jong- Bo K. Alstroemeria plants and its biotechnological applications. J Plant Biotechnol. 2012; 39: 219-224.

6. Anonymous. Growth of the cut flower industry in Kenya; 2006. Available: www.kenyarep-jp.com/business/ industry/f_index_j.html\#Growth

7. Papageorgiou I. Effect of growth retardants on growth and flowering of Lavendula stoechas, grown in plastic greenhouse. Chania (Greece). 1997; 62.

8. Healy WE, Wilkins HF. Responses of Alstroemeria 'Regina' to temperature treatments prior to flower inducing temperatures. Scientia Horticulturae. 1982; 17: 383-390

9. Pobudkiewicz A, Nowak J, Podwyszynska M, Przybyla A. The effect of growth retardants on growth and flowering of dwarf alstroemeria. Acta Agrobotanica. 2000; 53(2): 77-84.

10. Pobudkiewicz, A. 2008 The influence of growth retardants and cytokinins on flowering of ornamental plants. Acta Agrobotanica. 61(1):137-141.

11. Bhattacharjee, S. K. 1984. Effect of growth regulating chemicals on growth and tuberous root formation of Dahlia variabilis. Punjab Horticultural Journal, 24:138-144.

12. Karaz, S. and Karaguzel, O. 2010 Influence of growth regulators on the growth and flowering in dahlia (Dahlia variabilis) cv. Charmit. European Journal of Scientific Research 45(3): 498-507.

13. Kumar, R., Ahmed, N., Singh, D. B., Sharma, O. C., Shiv, L. and Salmani, M. M. 2013. Enhancing blooming period and propagation coefficient of tulip (Tulipages neriana L.) using growth regulators. African Journal of Biotechnology, 2(2): 168-174.

14. Sharifuzzaman, S. M., Ara, K. A., Rahman, M. H., Kabir, K. and Talukdar, M. B. 2011. Effect of $\mathrm{GA}_{3}, \mathrm{CCC}$ and $\mathrm{MH}$ on vegetative growth, flower yield and quality of chrysanthemum. International Journal of Experimental Agriculture, 2(1): 17-20.

15. Pobudkiewicz, A. and Treder J.2006. Effect of flurprimidol and daminozide on growth and flowering of oriental lily 'Mona Lisa'. Scientia Horticulturea. 110(4): 328-333.

16. Blomme, R. and Dambre, P. 1982. Problems in the culture of Alstroemeria. Verbondhieuws-Voor -de- BelgischeSierteelt, 28(5): 221-227.

17. Qiu, W. D. and Liu, K. B. 1989. Effects of paclobutrazol and B-Nine on stem elongation and flowering characteristics of chrysanthemum. (Chinese). Plant Physiology Communications. 6: 31-33.

\section{How to cite this article:}

Raiz Ahmed Lone, Imtiyaz Tahir Nazki, Nelofar and Gazanfar Gani. 2020. Influence of Growth Retardants on Flowering of Potted Alstroemeria (Alstroemeria hybrida L.). Int.J.Curr.Microbiol.App.Sci. 9(10): 2384-2390. doi: https://doi.org/10.20546/ijcmas.2020.910.285 